\title{
Professional ethics, engineering and energetic issues
}

\author{
Alice Ponchio ${ }^{1}$, Alberto Mirandola ${ }^{2, *}$ \\ ${ }^{1}$ Department of Philosophy, University of Padua, Padua, Italy \\ ${ }^{2}$ Department of Industrial Engineering, University of Padua, Padua, Italy \\ Email address: \\ aliponc@hotmail.com (A. Ponchio), alberto.mirandola@unipd.it (A. Mirandola)
}

\section{To cite this article:}

Alice Ponchio, Alberto Mirandola. Professional Ethics, Engineering and Energetic Issues. American Journal of Energy Engineering. Vol. 2, No. 4, 2014, pp. 87-95. doi: 10.11648/j.ajee.20140204.11

\begin{abstract}
Engineering is an interdisciplinary area, where interaction of technical and socio-economic dimensions continuously occurs in the professional practice. The ethical aspects of the relationships between engineers and society have been particularly emphasized in the recent years. In fact, the main engineering societies set up their own codes of ethics and many engineering departments worldwide introduced engineering ethics in their curricula. After introducing the concept of professional ethics and its connection with the deontological codes of professional orders, this topic will be considered in close relation to the profession of engineering and with particular attention to the energetic and environmental issues. This not only in order to give an account of professional codes, but more over to highlight how professional ethics includes and at the same time goes beyond them. Professional codes derive from two features of the profession: autonomy and self-regulation. One of the main aims of the codes is to regulate the asymmetrical relationship between professional and client in order to maintain the fiduciary nature of this relationship. This is highlighted through the analysis of two professional engineering codes. The ethical dimension helps revitalize and give meaning to professional codes and law: if a good professional life is to be conducted, it is necessary to combine the use of legal and professional guidance with an ethical structure, which brings us back to the human being and his/her personal sense of responsibility.
\end{abstract}

Keywords: Professional Ethics, Ethical Codes, Engineering, Energy, Environment

\section{Introduction}

While each animal has been provided by nature with some of its own abilities, which are necessary to survive and are similar to those of the other animals of the same family, man1 has no intrinsic material ability. Nonetheless he is a thinking being and has been equipped with hands. He can thus conceive and build what is needed to survive and live in a given environment. In other words, he can use technique to compensate for his lack of specific abilities. In addition, man can not only think about the present, but also use his mind and experience to estimate what will be needed in the future and act accordingly. So, while animals adapt themselves to the environment, man can modify the environment to make it more suitable to his needs. These characteristics allow man to live in and face a great variety of different situations and to live in a community to better exploit the available resources.

The latter point expresses another feature of the human

1 In this paper the word "man" is used to signify "human being" (man or woman), with no reference to sex. being: he/she is not only a thinking being, but also a social one. Indeed he/she can and does live in a community. To do this, suitable organization is needed, with the proper diversification of abilities. Inside this organization, each individual assumes a defined role, which implies duties and rights. To live properly in a community, rules must then be developed and each person has to comply with them. As we know, these rules are of different kinds: behavioral, conventional, social, economic, legal, and ethical. Each kind of these rules regulates different aspects of human life, such as personal, public and contractual relationships, domestic and professional life.

This paper deals with the role of a specific kind of rules in a precise area of human life: the role of ethics in professional life. More specifically, the role of ethics in the profession of engineers and its importance in the education of engineering students will be analyzed.

The weight of these aspects is indeed increasing in the contemporary world. Engineers typically work in the field of science and technique. They are particularly suit to creating and building devices, instruments and systems useful to the 
community. The way of working of engineers has been characterized by a continuous and progressive evolution, starting from the activity of artisans (skilled manual workers) and inventors (having not only manual, but also mental skill and creativity) up to the interdisciplinary and integrated work, based on scientific knowledge, of modern engineers.

The complexity of the modern world makes the work of engineers highly diversified and ethically challenging. As will be analyzed in the first and second section, the profession of engineers as profession implies ethical regulations, which cannot be substituted by the legal ones. On the other hand, engineers' work brings about remarkable responsibility toward individuals as well as communities. The results of engineers' work often involve consequences, which raise ethical questions, such as, for instance, those related to the environmental impact of specific kinds of techniques and the sustainability of resources.

This paper is divided into eight sections. The first and the eighth ones have an introductory and conclusive function. The second one deals with the definition of the concept of profession and its implications; the third with the nature and the goals of professional codes as regard to the law. In the fourth section, two important ethical codes of engineering are analyzed (the NSPE and ASME codes). In the fifth section the energetic and environmental implications of the engineers' profession are examined, while the need for a wider ethical dimension in professional life (with specific attention to engineers' professional life), which goes beyond professional and legal codes, is highlighted in the sixth. The seventh section examines the structure of the course of ethics for engineers organized within a European University.

\section{Professional Ethics}

"Profession" is generally understood as an activity where a person provides a service on the base of his/her capacities, abilities and knowledge in order to obtain the goods to support him/herself. In these terms being a teacher, a baker, a plumber, a cashier, a secretary, a lawyer, etc., is having a profession. Besides this broad meaning of the term there is a more specific one. Narrowly "profession" is a working activity of high qualified nature carried out by a human being who has acquired specialist competence through academic and practical training. In this sense architecture, engineering, lawyer, medicine and the like are professions. The latter meaning of profession is relevant for ethical research and the following considerations will refer to it.

According to the most reputable studies on this matter, there are three key-criteria identifying a "profession" in its narrow sense: 1) intellectual education; 2) specialist competences and abilities; 3) institutional instruments that permit a responsible practice of these competences and abilities 2. The expression "institutional instruments" indicates on the one hand obligations that constitute professional codes and that every professional as such

2 Parsons [1] Vol. XII, pp. 536-541, 545-547 commits himself to honor. On the other hand, "institutional instruments" means the bench within the professional group that has the function of verifying the adherence to those codes.

Furthermore when we use the word "profession" what we mean is a practice. Quoting the philosopher Alasdair McIntyre, a practice is "any coherent and complex form of socially established cooperative human activity through which goods internal to that form of activity are realized in the course of trying to achieve those standards of excellence which are appropriate to, and partially definitive of, that form of activity" 3 .

A practice is therefore a cooperative activity with internal goods and standards of excellence that define it. Internal goods are not an individual's property and possessions (like fame or wealth, which are external goods) but shared and inclusive ones, i. e. goods for the whole community which participates in a practice. For example the development of a more sustainable and efficient energy system would be a good for all engineers and not only for the one who developed it.

A profession is then a common undertaking implying behavior to which practitioners conform. But this very comprehensive undertaking distinguishes itself from a mere technical activity. A technical activity is aimed at some further end and therefore has an instrumental value. On the contrary, a profession has internal goods and thus an intrinsic value. Indeed, while the value of a technical activity depends on its effectiveness in the achievement of the aimed end and on the value of the latter one (we praise the activity of a shoemaker, for example, calling it "good" if the shoes he/she has made are good, while we despise that activity, calling it "bad" if the shoes are bad), the value of a profession does not depend on a singular good it achieves, but on the practice of the profession itself. A good professional activity produces the internal goods of the profession. This means that the achievement of a good professional activity is inherent in the professional. Consequently, being a professional implies not only having technical knowledge and ability, but also knowing the internal goods of the profession and carrying them out.

Beyond these aspects of the concept at issue, its etymological derivation is also very important for indicating the characteristics of the professional. The word "profession" comes from the Latin profiteri, which means "to declare aloud", "to state openly". According to this meaning, a professional publicly accepts a special way of life: he/she declares aloud his/her competence and states openly he/she will use the necessary knowledge in the client's interest and not his/her own.

A profession is then a collective activity that is aimed at specific internal goods and implies a public declaration of competence and of specialist commitment in behalf of the client. This involves institutions of self-regulation and selfjustice. These features are the main objects of reflection

3 McIntyre [2], p. 187. 
about professional ethics.

\section{Professional Codes}

Professional codes are forms of self-regulation concerning professional groups. They arise from the intrinsic asymmetry characterizing every relationship between a professional and the person who addresses him. This asymmetry lays in the origin and in the essence of these relationships as such: when someone has a (medical, technical, juridical...) problem he/she appeals to a specialist in order to solve it. This specialist guarantees, "declares aloud", to have the necessary knowledge and ability to help him/her. There is always a disparity between the professional and the client: the latter is a person in need of help; he/she does not have the power to solve his/her problem by him/herself and so is dependent upon the former for the technical knowledge necessary for a choice and the professional's competence to carry out the choice once it is made. This asymmetrical relationship can be interpreted on the basis of four models:

1) According to a commercial model, the professional relationship is regulated by minimal market-place morality, which allows everything except for compulsion and deception. Therefore, someone who needs engineering consulting will address the engineer knowing that the only rule governing their relation will be that of the market.

2) The corporative model considers the relationship in a paternalistic way. This model emphasizes the role of the professional: he/she is the person who establishes what decision is right in that particular case. The client has no chance to decide on his/her own or to explain his/her values and priorities.

3) The autonomist model is essentially the opposite of the corporative one. According to it, the professional must totally represent the interest of the client with no possibility to give advice or opinions that differ from the client's point of view.

4) The interaction-model is based on an interaction between professional and client in order to reach the most equally shared decision: on one hand the professional provides the competence to satisfy the needs of the client, on the other hand the client makes his/her values and priorities known.

Since asymmetry derives from the specific nature of professional-client relationships, it cannot be eliminated. Nonetheless it can be limited and moderated; this moderation is the main goal of professional codes. This is not a question of mere regulation or balance, but a genuine ethical task. Indeed the special fiduciary character of professional relationships is at stake in the limitation of the asymmetry. In a state of vulnerability and inequality, the client is forced to trust the professional. As a matter of fact a professional relationship springs not only from someone's need for specialist competence and from the professional's competence-guarantee but also from needy person's belief in the professional. When we are in need of professional competence we do not look for a professional in general, but for the one we can trust. The fact that a professional is successful and competent is not enough for us to choose $\mathrm{him} /$ her as a partner in a professional relationship. What we want is someone who is worthy of our confidence. Thus the professional relationship is not only an asymmetrical one, but also a fiduciary one.

The moderation of asymmetry aims to safeguard this fiduciary relation between the professional and the client within this non-eliminable asymmetry. Through this moderation, professional codes aspire to establish an interaction between professional and client according to the fourth model described above.

Since professional codes arise from a genuine ethical problem implicated in the nature of every professional relationship, they are ethical codes. These codes are also called "deontological codes". The adjective "deontological" derives from the ancient Greek déon which means "duty". A deontological code is therefore a set of ethical duties.

Emphasizing the ethical nature of professional codes is not trivial. Nowadays we are confronted with a progressive expansion of the role of law in the regulation of professional relationships. When the client thinks that a professional's performance has been not satisfactory, he/she often appeals to the jurisdictional system. In order to avoid legal worries, the professionals safeguard themselves in advance, taking out policies. This phenomenon is something problematic with regard to the very features of the relationship we are considering, namely its being asymmetrical and fiduciary.

Of course it is legitimate to use law to regulate the professional-client relationship, if the rights of the partners are at issue. Nonetheless, law is only able to regulate some aspects of a professional relationship, not the entire thing. As claimed above, this relationship is one between a person seeking help and a professional that possesses the expert knowledge that the client needs. Therefore there is an inherent inequality in this relationship that places the preponderance of power in the professional's hands. Law regulates relations between partners in a contract. Since in the contract the partners are equal and their relationship is a symmetrical one, the law can regulate it. On the contrary, the professional relationship cannot be considered a contract because one part (the client) is dependent upon the professional's services. This is why the appeal to law as the only regulatory instrument is not sufficient.

Moreover the recourse to legal remedies in every case where the partners disagree is dangerous for the relationship itself. This practice leaves no room for trust neither from the client, who is ready to use legal means to deal with every type of disagreement, nor from the professional, who takes measures in advance to safeguard himself. This leads to the failure of the fiduciary relationship between the professional and the client, as well as their professional relationship as such.

Since it cannot regulate the professional relationship as such, law cannot replace the professional codes. On the contrary, professional codes and law must collaborate. Indeed 
within the structure of these codes and legal regulation lie essential elements that guide and regulate professional life: examining the law and the professional codes, a professional can sufficiently and clearly identify obligations and responsibilities that must guide his/her professional activities. The awareness of the importance of this dual system of regulation and of the differences between strictly legal and professional obligations is very important.

\section{Codes of Ethics of Engineering Societies}

As emphasized in Section 1, Engineers have a great responsibility towards society and individuals. Through their work, they have a strong impact on the everyday and future life of men and animals; they can both greatly contribute to public welfare and cause damages; they can spread either good or bad information about technical issues, thus influencing the decisions of politicians; they can improve people's life style, but also negatively modify the environment.

The consciousness of this great amount of responsibility was the reason for many professional associations of engineers to establish ethical codes. One of the most advanced and detailed codes is that of the U.S. National Society of Professional Engineers (NSPE) [3]. Another, more concise, but extremely similar in the main concepts, is the Code stated by the American Society of Mechanical Engineers (ASME) [4].

The NSPE Code is divided into three parts:

- fundamental canons

- rules of practice

- professional obligations.

The ASME Code is divided into:

- fundamental principles

- fundamental canons

- the ASME Criteria for interpretation of the Canons

The main principles of both the NSPE and the ASME Code state that engineers must uphold and advance the integrity, honor and dignity of their profession.

In the following we will refer to the fundamental canons of these two codes, emphasizing the duties they impose on the profession of engineering. In general, these canons consider the relationships between engineers and society, engineers and clients, engineers and colleagues; they delineate how engineers should act and behave.

According to the NSPE-Fundamental Canons, engineers, in the fulfillment of their professional duties, shall:

1) Hold paramount the safety, health and welfare of the public;

2) Perform services only in areas of their competence;

3) Issue public statements only in an objective and truthful manner;

4) Act for each employer or client as faithful agents or trustees.

5) Avoid deceptive acts.
6) Conduct themselves honorably, responsibly, ethically and lawfully so as to enhance the honor, reputation and usefulness of the profession.

According to the ASME code the fundamental canons are that:

1) Engineers shall hold paramount the safety, health and welfare of the public in the performance of their professional duties.

2) Engineers shall perform services only in the areas of their competence.

3) Engineers shall continue their professional development throughout their careers and shall provide opportunities for the professional and ethical development of those engineers under their supervision.

4) Engineers shall act in professional matters for each employer or client as faithful agents or trustees, and shall avoid conflicts of interest or the appearance of conflicts of interest.

5) Engineers shall build their professional reputation on the merit of their services and shall not compete unfairly with others.

6) Engineers shall associate only with reputable persons or organizations.

7) Engineers shall issue public statements only in an objective and truthful manner.

8) Engineers shall consider environmental impact in the performance of their professional duties.

As we can see, the canons of the two codes are very similar. The first one is a milestone: engineers shall hold paramount the safety, health and welfare of the public in the performance of their professional duties. This sentence includes a variety of items, actions and rules of practice, because engineers work in widely diversified fields of activity: process industry; manufacture of machines, plants and products; design, construction and maintenance of buildings, roads, bridges; energy and the environment; public administration; self-employment; etc. Safety, health and welfare should be considered in all the steps of engineers' activity: design, construction or manufacture, operation, maintenance, monitoring and control, decommissioning. The main point of this canon is the requirement that engineers be aware of the dependence of the lives, health and welfare of the general public upon their judgment and act in accordance with this huge amount of responsibility. This implies working in conformity to safety standards, constantly reviewing the safety of their plans, designs or products, and informing the proper authorities when risks arise4 [ASME, first criterion of

4 In technical risk analysis, risk is commonly defined as "the statistical expectation value of unwanted events, which may or may not occur" (Hansson, 2004 [5]; see also Kermisch, 2010 [6]). A European Commission Report, (2000, p. 18 [7]) suggests that "risk is widely recognized as a function of the probability and severity of an adverse effect/event occurring to man or the environment following exposure, under defined conditions, to a hazard". The notions of risk and responsibility are apparently distinct, because the previous definitions of risk are disconnected from the risk factors. But they relate to each other in the risk management process: risk assessment consists in the identification and quantification of risk and is disconnected from responsibility; but the acceptability and management of risk involves a question of "values" and is 
interpretation].

This first canon includes particular attention to environmental health: this aspect of the codes will be discussed in the following section.

The second canon of the two codes is also the same: "Engineers should perform services only in areas of their competence". This duty is developed in the fifth canon of the ASME code: "Engineers shall build their professional reputation on the merit of their services and shall not compete unfairly with others". These statements require engineers to accept assignments only if qualified and to be honest about their competence and qualifications. Furthermore, they are required to continue their professional development through continuing education and also provide opportunities for the professional development of colleagues under their supervision.

The need for fairness and truthfulness in engineers professional life is also expressly stated in both codes: the NSPE code declares in its third canon and the ASME code in its seventh one that engineers shall "issue public statements only in an objective and truthful manner" This is a very important duty for engineers. It requires them to correctly inform people, decision makers and politicians about the issues of their competence and express technical opinions that are based upon their appropriate knowledge and competence, without being inspired by personal interest.

However, truthfulness and fairness are not only required when informing people and expressing professional judgements, but also in professional relationships: "Engineers shall act in professional matters for each employer or client as faithful agents or trustees, avoiding conflicts of interest and respecting the proprietary information and the intellectual property" $\left[\right.$ ASME $4^{\text {th }}$ canon; see also NSPE $4^{\text {th }}$ canon]. This canon commits engineers to avoiding every source of conflict of interests with employers and clients and to act with fairness and justice to all parties. This implies on the one hand that, "before undertaking work for others in which engineers may make improvements, plans, designs, inventions, or other records which may justify seeking copyrights, patents, or proprietary rights, engineers shall enter into positive agreements regarding the rights of respective parties" [ASME Criteria for Interpretation 2.4.1], and, on the other, that they admit their own errors [ASME Criteria for Interpretation 2.4.m].

\section{Ethical Aspects of the Energetic and Environmental Issues}

As seen in the previous section, the first canon of both codes implies particular attention to environmental health, which is closely related to the exploitation and use of energy resources. This concept is explicated in the eighth canon of the ASME Code:"Engineers should consider environmental

strongly related to responsibility. On the other hand, the assessment step also involves technical skills. So, engineers are interested in the entire risk management process. impact and sustainable development in the performance of their professional duties".

The fact that the ASME Code makes it a precise duty of engineers to consider environmental impact and the sustainable development in their work is worth noting. Indeed this is a very modern issue, since people have become conscious of environmental problems only in relatively recent years. In particular, the concept of sustainability is very important, despite its only recent relevance, because it has fundamental implications and consequences on our lives and on those of future generations. This concept is closely connected to science, technology and economy in a way which it is worth briefly explaining in the following.

Sustainability is not simply referred to the impact of certain practices on the environment, but is a more complex concept, because it deals with:

- the resources needed to sustain the human population (more than 7 billion in 2014 and still increasing);

- the social and economic impact;

- the impact on the environment;

- the technological constraints.

According to N. Lior [8], "sustainable development is of vital importance to humanity's survival" and is based on the "adequate satisfaction of quantitatively defined and interrelated economical, environmental and social criteria". However "it is very difficult to quantify environmental and social metrics". Thus, "sustainability is more and more extensively used erratically and often improperly and even fraudulently over the entire social spectrum by governments, institutions, business, industry, schools and individuals".

These features are particularly challenging for engineers: they should take these concepts into account in performing their professional activities, but without falling into demagogy. For example, when it comes to resources, energy and social organization, some opinion leaders of the so-called "green people" think that generally it would be desirable to let nature simply run with its own rhythms. This would be possible in a world less crowded than the present one, but today it is necessary to use the possibilities offered by technology, which is a valuable means that can prevent natural disasters or other dangerous events to occur. Engineers should distinguish utopian projects and their effects from realistic ones. Indeed, rather than utopian projects, long-term energy policies are thus fundamental. Engineers should realize that energy conservation is to be a goal in all fields of activity: so, seeking high efficiency and rational organization of energy systems is paramount. As for renewable energy sources, their real potential must be explained to the people, to avoid unrealistic reliance upon them. These issues are generally very complex: in this case, it is very important to be able to "reason by systems", which is typical of modern engineers. In any case, the so-called "3 E's" (Energy, Environment, Economy) must always be considered, because these three aspects are closely connected to each other.

Of course, there is a conflict between the need for resources of our crowed world and the environmental impact: 
finding the most acceptable compromise between these two features is a very challenging problem for politicians, scientists, economists and engineers.

\section{Beyond Law and Professional Codes}

No doubt the canons and the duties briefly exposed are very important for engineers' professional life. However, many questions and dilemmas about the correct concrete professional conduct cannot often be answered by professional codes (and even less by law). Consider this case: in designing a plant, which could be dangerous for the environment, an engineer has to do the interests of the client as well as the ones of the society, to be truthful about the impacts of its work and to find a way to develop the plant standards of safety and environmental sustainability without forgetting economic, environmental and risk factors. Or consider this one: in a period of economic crisis the engineer manager of a factory faces the problem of dismissing some workers to save the company. Like many others, these are very difficult tasks, which no deontological rule says how to solve. In many cases the solution of a problem or of a problematic situation in professional life is indeed up to the professional itself. This requires the professional to look at law and professional codes and to judge beyond them about what is the right thing to do.

Judging beyond law and professional codes does not imply stating their invalidity but interpreting them within a wider ethical context. This wider context consists in a sound ethical structure of the person and in his/her sense of responsibility. In order to answer the moral questions being raised in professional life, legal and professional guidance has to be combined with an individual's sound ethical structure and with his/her sense of responsibility.

This involvement of the person in the identification of the morally right action in a certain situation is a very important, often neglected aspect of professional ethics. As a matter of fact, we frequently speak about professional ethics identifying it with the professional codes, and neither the general inadequacy of the codes when faced with some ethical problems nor the need for a wider ethical context are regarded. That is a dangerous mistake, because it misunderstands the role of professional ethics. The latter does not only provide a set of duties that we must fulfill, but furthermore deals with formation and development of an ethical character in the agents. Using a term that perhaps is no longer seen as current, professional ethics aims for the development of certain virtues in the professional.

A virtue is not a natural but a developed trait of character that we achieve through exercise and personal commitment. Quoting Aristotle:"None of the moral virtues arises in us by nature; for nothing that exists by nature can form a habit contrary to its nature [...].but the virtues we get by first exercising them, as also happens in the case of the arts as well. For the things we have to learn before we can do them, we learn by doing them, e.g. men become builders by building and lyreplayers by playing the lyre; so too we become just by doing just acts, temperate by doing temperate acts, brave by doing brave acts" 5 .

We can understand a virtue as the motivation to act rightly and appropriately. The rules, even those of a deontological code, cannot guide a professional activity without being interpreted in the light of the moral structure and motivation of the agent. The development of virtues is therefore indispensable for the rules to be effective.

Nevertheless the development of a virtuous character is not only relevant in cases when the guidance of deontological code or of law is lacking, but also indispensable for the practice of the profession itself. In the introduction the term "profession" has been defined as indicating a common activity that is aimed at specific internal goods. The achievement of these internal goods is closely related to the development of virtues. Quoting Alasdair McIntyre again,"A virtue is an acquired human quality the possession and the exercise of which tends to enable us to achieve those goods which are internal to practices and the lack of which effectively prevents us from achieving any such goods" 6 .

This means that being a professional, and not a mere technician, implies the development of motivations to act in a morally correct and appropriate way. Only through these motivations or virtues the goods internal to the profession can be achieved. Virtues are then necessary conditions for the profession.

Consider now the profession of engineering. By mutual consent it could be generally qualified as the discipline and profession that uses intelligence (ingenium), applying results in order to solve issues and to satisfy human needs. The internal good (or end) of this practice is then the solution and satisfaction of human problems and needs. What kind of virtues are required for the achievement of this internal good? In the following, four main virtues are listed, but others could be added to them.

The first virtue is benevolence. This is the virtue of being disposed to act for the benefit of others, quoting Immanuel Kant "an active practical benevolence" 7 which makes the welfare of others its end, as well as its practical counterpart. Benevolence implies then the capacity to recognize others' needs or problems and the readiness to solve them. This capacity does not merely imply being able to find the best technical solution for the case in question, but above all the capacity to have a comprehensive insight on the best technical solution that has moral relevance for the situation. This involves taking into consideration the client's needs and values, the economic factors as well as the environmental impact of the prospected solution and the possibility to use alternative energy resources.

Responsibility is also a relevant virtue. We can see it as a future-oriented virtue. Being responsible means indeed, on one hand, being able to foresee the effects of our deeds and, on the other, being committed to justify our actions and to

\footnotetext{
5 Aristotle [9], pp.28 f. (1103).

6 McIntyre [2], p. 191.

7 Kant [10], pp. 199 (6:449-452).
} 
pay for their consequences.

The third virtue which is required is courage. It consists in the capacity to not succumb to difficulties and to calmly face the risks and the uncertainties of some decisions and situations. This does not mean fearlessness, but, as Aristotle defined it, a "mean with regard to feelings of fear and confidence"8. Courageous is indeed not he who has no fear but he who finds the middle way between fear and fearlessness: "Though courage is concerned with feelings of confidence and of fear, it is not concerned with both alike, but more with the things that inspire fear; for he who is undisturbed in face of these and bears himself as he should towards these is more truly brave than the man who does so towards the things that inspire confidence. It is for facing what is painful, then, as has been said, that men are called brave. Hence also courage involves pain, and is justly praised; for it is harder to face what is painful than to abstain from what is pleasant"9.

The fourth virtue is practical wisdom, the virtue of deliberation and discernment 10 . It consists in the capacity to recognize the appropriate course of action that leads to the internal good of the profession in a very specific situation. This ability implies knowledge of the circumstances of the situation and of moral relevant features, the capacity to recognize human needs, the awareness of general legal and ethical duties and the skill to apply them to the very specific context as well as the awareness of the internal good of the profession. It also implies the skill of identifying the appropriate means for the intended end, the capacity to foresee the consequences of the action and to not succumb to difficulties. Practical wisdom is therefore the virtue that summarizes the others ("With the presence of the one quality, practical wisdom, will be given all the virtues" 11 wrote Aristotle) and orients them to the practice.

These four virtues are significant for the profession of engineering. If being an engineer means using his/her intelligence to solve human problems and satisfying needs, such a professional cannot lack the capacity to see human needs and the readiness to solve them as well as the disposition to do good for someone. As a matter of fact, for example, we do not regard as a good professional the person who does the profession only in order to earn money or to have a great reputation, but not in order to satisfy human needs. He/she may be successful and do great deeds but we do not consider him/her as someone who expresses the profession's internal good. Furthermore we call a "good

8 Aristotle [9], p. 65 (1115a).

9 Aristotle [9], p. 71 (1117a).

10 "The man who is without qualification good at deliberating is the man who is capable of aiming in accordance with calculation at the best for man of things attainable by action. Nor is practical wisdom concerned with universals only-it must also recognize the particulars; for it is practical, and practice is concerned with particulars. This is why some who do not know, and especially those who have experience, are more practical than others who know; for if a man knew that light meats are digestible and wholesome, but did not know which sorts of meat are light, he would not produce health, but the man who knows that chicken is wholesome is more likely to produce health." Aristotle [9], p. 146 (1141a-b). 11 Aristotle [9], p. 156-158 (1145a) professional" someone who is able to recognize the appropriate means to the good at issue, to foresee their consequences, to pay for them and who does not succumb to difficulties and uncertainties of everyday professional life. A good professional is then a person who can deliberate well, paying attention to the numerous factors of a situation.

Many professionals work in the area of self-employment, but others, as for example a lot of engineers, work within economic or industrial companies and may be leaders or have an important role within their organisation chart. Consequently, they are often involved in the so-called Corporate Social Responsibility (CSR) of the company, which is a form of self-regulation integrated into a business model, showing that the company monitors and ensures its active compliance with ethical standards, aiming at reaching some social good, beyond the interests of the firm and also beyond the spirit of the law. CSR covers both legal and moral responsibilities of the organization, which can be certified by accepting to be periodically controlled.

An international recognized voluntary certification is SA8000 (Social Accountability 8000), which is a management system standard modeled on ISO standards; it concerns some very important areas to be considered within the business activity: child labor, forced and compulsory labor, health and safety, freedom of association and right to collective bargaining, discrimination, disciplinary practices, working hours, remuneration. To gain and maintain this certification the company must go beyond a simple compliance to the standard, but also integrate it into its management systems and practices and demonstrate ongoing conformance with the standard, that is based on the principles of international human rights. As seen for a single professional, this management strategy of the company, which is voluntary, highlights an ethical attitude that goes beyond law, codes and rules.

Of course, a professional involved at high level in this kind of organization should have the characteristics that have been outlined in this paper; his/her behavior and way of working will be in agreement with practical wisdom.

\section{Ethics in Engineering Education}

The urgent need for a wider ethical structure also in engineering professional life has determined a lot of phenomena. The perhaps most striking are:

- The establishment of the scientific journal called "Science and Engineering Ethics", where discussions about the ethical issues involving science and technology are developed.

- The organization of curricula including engineering ethics throughout the world12.

The following will be focused on this second phenomenon. Generally speaking, in these curricula two teaching approaches might be used:

1) introducing ethical concepts and examples during some

12 See, for example, Berry et al. [11]. 
engineering modules;

2) introducing a specific module into the curriculum of engineering students.

Yet both approaches are problematical. The problem with the first one is that the ethical topics should be discussed by engineering professors, but most of them are generally not prepared to introduce ethics into their courses: they are most comfortable with quantitative concepts and often do not believe they are qualified to lead discussions on ethics. The problem with the second one consists in the fact that this module should be taught by an expert teacher, for example a teacher of philosophy, and this choice could provide the false message that ethics is something detached from engineering profession.

In order to not incur in these two problems, in a European University a course of "Ethics for Engineering Students" has been organized with a close collaboration between a professor of philosophy and a professor of engineering. The basic theoretical concepts are introduced and deepened by the professor of philosophy in the first part of the module, which has three main targets:

1) To introduce the engineering students to the specific language, problematic and particularities of ethics;

2) To pay attention to ethical questions often related to the profession of engineers. The main aspect which is analysed is the necessity to keep faithful relationships between engineers and clients in spite of the noneliminable asymmetry characterizing them;

3) To show that the ethical thinking should not be confused with the legal implications of one's actions or with deontological codes: ethical thinking must go beyond legal and professional duties and lead engineers to use judgment in order to find the ethically right action-strategies. This requires the development of a virtuous character in a process, which considers the man not only as a professional, but as a whole.

The second part of the course, coordinated by a professor of engineering, consists of a series of speeches and interviews of professionals who are leaders in different fields, in order to give the students a set of experiences related to diverse professional situations. These lectures are developed as "open discussions" about typical ethical issues occurring in industry, public administration, self-employment, etc.

An important issue discussed during this second part of the course is sustainability, a topic that involves men, animals and the environment and the importance of which has already been emphasized in section 5. Different viewpoints can be expressed about it, so lively discussions can arise13. Another central item is the concept of leadership. The reason for choosing this special topic lays in the fact that many engineering students will probably become leaders of a company, an industry, a group of people in their future working life. In engineering education important issues are thus to explain what it means to be a leader and to consider how one can be a leader, and what characteristics a leader

13 See, for instance, V. Miltojevic [12] should have.

The concept of leadership is not presented as indicating a merely hierarchical position. According to the content of the lectures, a leader should be a source of inspiration and confidence, willing to sustain and guide the subordinate individuals, to give sense to their work with the example of his/her own behaviour. Leadership is not a target to be reached, but a road to walk day by day; a road that requires self-sacrifice, patience and also humility; as a consequence, a mature system of relations between colleagues and coworkers will be established. Of course, the results cannot be obtained immediately, but in the long term, which requires perseverance and patience. In this way human and material resources will be better exploited, conflicts will be more easily reconciled, the general organisation of the team (or company, etc.) will be improved, and the atmosphere inside the team will be serene and relaxed.

The module "Ethics for Engineering Students" is offered to all Engineering students as a free-choice module: they can choose it or not. It is worth noting that the students who seem to be more interested in this module are generally those who attend the Energy Engineering Degree Course: it probably means that the students who are inclined to deepen energetic and environmental topics are also interested in ethical issues, which are closely connected to the profession of Energy Engineers.

\section{Conclusions}

In this paper professional ethics has been analyzed in close connection to the profession of engineering, with particular emphasis on Energy Engineering. The analysis has first stressed the twofold dimension of professional ethics. This dimension is rooted in two very ethical issues implied in the concept of profession as such: the need to preserve the fiduciary relation that characterizes every client-professional relationship and the achievement of the internal goods of the profession itself. Thus on the one hand professional ethics reminds us what we ought to do in order to encourage the fiduciary relation between client and professional through the professional codes. From this point of view two engineering codes and their main topics have been analyzed: the NSPE code and the ASME code. On the other hand, it has been stressed that the role of ethics in professional life goes beyond recommending what we ought to do and moreover suggests us how we have to act and what dispositions or motivations we are required to develop in order to be good professionals. This second aspect of professional ethics is unfortunately often overlooked or completely misunderstood by moralists who work on professional ethics as well as by professionals. But if a profession is a practice, if a practice is aimed to its internal goods and if the achievement of these goods needs the development of specific dispositions or virtues, virtues are then necessary conditions for the profession itself. If this argument is valid, it has two relevant implications. It firstly commits every professional to enhancing his/her own ethical character and to developing and cultivating virtues. Furthermore it 
implies that the formation of new professionals should not be merely technical but also ethical. The validity of the argument and the acknowledgment of a relevant weight of ethical education seems to be confirmed by experience, that is by the fact that increasingly numerous curricula including ethics are organized in academic departments that traditionally are meant to be technical; an example has been examined in Section 7.

\section{References}

[1] Parsons T., Professions. In: Sillis D.L., editor. International Encyclopedia of the Social Sciences. New York USA: The Macmillan Press - The Free Press; 1968. Vol. Xii, p. 536-541, $545-547$

[2] McIntyre A., After Virtue: A Study on Moral Theory. London UK: Duckworth 1985.

[3] National Society of Professional Engineers (NSPE): Code of Ethics for Engineers; Publication \#1102, 2007.

[4] American Society of Mechanical Engineers (ASME): Code of Ethics of Engineers, June 10, 1998.
[5] Hansson, S., 2004. Philosophical perspectives of risk. Techné, $8(1), 10-35$.

[6] Kermisch, C., 2010. Risk and Responsibility: a Complex and Evolving Relationship. Science and Engineering Ethics.

[7] European Commission, 2000. First report on the harmonisation of risk assessment procedures, http://ec.europa.eu.

[8] Lior, N, 2011, Sustainability Ethics: a Call for Damage Control and Prevention; Proceedings of ECOS 2011, Novi Sad, Serbia, July 2011.

[9] Aristotle, Nicomachean Ethics. Trans. by D. Ross, Oxford University Press, 1980.

[10] Kant I., Metaphysics of Morals. Edit. by Gregor M. Cambridge UK: Cambridge University Press; 1998.

[11] Berry, B.E, White, G.K. and Arnas, A.O.: Engineering Ethics Education: a military Academy Point of View; Proceedings of ECOS 2011, Novi Sad, Serbia, July 2011.

[12] Miltojevic, V.: Education and Engineers' Environmental Ethics, Proceedings of ECOS 2011, Novi Sad, Serbia, July 2011. 